\title{
EFFECT OF PONTIC FRAMEWORK DESIGN ON THE FRACTURE RESISTANCE OF IMPLANT-SUPPORTED ALL- CERAMIC FIXED PARTIAL DENTURES
}

\author{
Ozgur INAN ${ }^{1}$, Asli SECILMIS' ${ }^{2}$, Oguz ERASLAN ${ }^{3}$
}

1- DDS, PhD, Professor, Department of Prosthodontics, University of Selcuk, Faculty of Dentistry, Konya, Turkey.

2- DDS, PhD, Assistant Professor, Department of Prosthodontics, University of Gaziantep, Faculty of Dentistry, Gaziantep, Turkey.

3- DDS, PhD, Assistant Professor, Department of Prosthodontics, University of Selcuk, Faculty of Dentistry, Konya, Turkey.

Corresponding address: Assistant Professor, Asli Secilmis - University of Gaziantep, Faculty of Dentistry, Department of Prosthodontics - 27310 Gaziantep/Turkey - Phone: +903423610610 - Fax: +903423610610 - e-mail: acarasli@hotmail.com

Received: September 2, 2008 - Modification: November 10, 2008 - Accepted: May 18, 2009

\begin{abstract}
$O$

bjective: The purpose of this study was to compare the fracture resistance of implant-supported all-ceramic fixed partial dentures, which have three different pontic designs. Material and Methods: Two implants were placed in a metal model simulating mandibular left second premolar and mandibular left second molar. Thirty standardized 3-unit all-ceramic fixed partial dentures with biconvex, convex or concave pontic designs were fabricated using IPS e.max system $(\mathrm{n}=10)$. Afterwards, specimens were centrally loaded on the pontics until failure with a universal testing machine. Results were analyzed by Kruskal-Wallis and MannWhitney U tests at 5\% significance level. Results: The fracture resistance values of all-ceramic fixed partial dentures designed with biconvex, convex or concave pontics were $349.71,438.20$ and $300.78 \mathrm{~N}$, respectively. There were no statistically significant differences between the fracture resistances of the groups ( $p>0.05$ ), except for convex and concave groups $(\mathrm{p}<0.05$ and $\mathrm{p}=0.009$, respectively). Conclusions: Convex design showed the best mechanical properties as demonstrated by the high values of fracture resistance.
\end{abstract}

Key Words: Pontic. Design. Dental implants. Fixed prosthesis.

\section{INTRODUCTION}

The rising interest in esthetic dentistry by patients over the past decade has led to an increased demand for metalfree restorations in the posterior as well as anterior region ${ }^{25}$. Because of their esthetics and biocompatibility, many patients prefer all-ceramic crowns to metal-ceramic crowns. Nowadays, strong ceramic core materials have been developed to support the weaker veneering ceramic materials, particularly for the use of all-ceramic restorations in the posterior region ${ }^{6}$.

Lithium-disilicate glass-ceramic, glass-infiltrated alumina and tetragonal stabilized zirconia are useful for three-unit bridges in present time ${ }^{15}$. In 1998, three-unit bridges made of lithium disilicate glass ceramic were introduced for the replacement of a missing tooth up to the first premolar, where the recommended connector crosssection area is $16 \mathrm{~mm}^{2,20,23}$. In 2005, an improved press ceramic material called IPS e.max Press was introduced to the market. There are limited data available on IPS e.max Press ceramic. This pressed ceramic is intended to expand the range of indications of Empress 2. While it features similar physical properties as the latter, its translucency has been improved. IPS e.max Press system encompasses a highstability framework material which consists of lithium disilicate ( $2 \mathrm{SiO}-\mathrm{Li}_{2} \mathrm{O}$ ). The restorations can be customized either by using a layering technique based on fluorapatite glass ceramic or by using the staining technique ${ }^{24,26}$. As far as it could be arcertained, there is no study concerning the resistance of implant-supported IPS e.max Press restorations in the literature.

As they have aided overcoming several of the limitations encountered with prosthetic solutions, dental implants have become a reliable alternative in the treatment of partial or complete edentulism. Studies evaluating the long-term prognosis of implant-supported restorations have been published $^{2,9}$. It is well known that the load bearing capacity of bridges depends on the ceramic material's properties, but also to a high extent on the size, shape and position of the connectors, as well as on the span of the pontics ${ }^{20}$, the fabrication technique, the surface finish of the crowns and the luting method ${ }^{1,3,4}$.

Pontic designs were well described for situations that require pontics in the fabrication of fixed partial dentures. These designs are include: saddle (ridge lap), modified ridge lap, hygienic (sanitary), conical and ovate. Pontics of bridges 
have to fulfill esthetic, mechanical, functional, and hygienic requests in prosthetic dentistry. Proper design is more important for cleanability and good tissue health than the choice of materials ${ }^{22}$.

When teeth are lost, alveolar resorption and remodeling reshapes the edentulous area. The final healed ridge shape may be an even greater departure from the orginal configuration. The neighboring and opposite teeth may also be affected from the loss of tooth. The tooth opposite the gap can begin to drift out of its socket. In these cases, modifications must be made in basic tooth morphology for pontic $^{22}$. Stress distributions in a prosthesis can be quite complex. If the pontic design is altered, the characteristic stress pattern can be optimized to improve the survival time of implant-supported all-ceramic bridges. The purpose of the the study was to evaluate the effect of different frameworks designs (concave, convex and biconvex pontic design) on fracture resistance of all-ceramic systems by loading test. The null hypothesis tested was that the different pontic designs do not affect the fracture resistance of allceramic restorations.

\section{MATERIAL AND METHODS}

To simulate clinical conditions, 2 implants (ITI solid screw implants, 3.8-mm diameter, 10-mm bone sink depth; Straumann AG, Waldenburg, Switzerland) were arranged in a stainless steel model. The distance between the centres of the implants was $19 \mathrm{~mm}$. This distance was approximately corresponded to a three-unit dental bridge from a second lower premolar to a second lower molar. The cement retention abutments (solid abutments; Straumann AG) were tightened to $35 \mathrm{Ncm}$ using the implant manufacturer's torque device (Straumann AG).

Three 3-unit wax frameworks were fabricated. The occlusal and wall thickness of all ceramic cores was 0.8 $\mathrm{mm}$. The pontics were designed in a biconvex, convex or concave form. Biconvex form designed as the control group, $1 \mathrm{~mm}$ curves to the direction of the occlusal surface (convex form) and $1 \mathrm{~mm}$ curves to the direction of the gingival surface (concave form). The connectors were $4 \mathrm{~mm}$ in height and 4 $\mathrm{mm}$ in width. Convex and concave pontics had an occlusogingival height of $4 \mathrm{~mm}$, and a bucco-lingual width of 4 $\mathrm{mm}$ whereas biconcave pontic had an occluso-gingival height of $6 \mathrm{~mm}$, and a bucco-lingual width of $4 \mathrm{~mm}$. A high viscosity (Zetaplus; Zhermack, Rovigo, Italy) and low viscosity hydrocompatible condensation silicone (Oranwash L; Zhermack, Rovigo, Italy) were used to fabricate indexes on a wax-up of the first specimens. This index was used to prepare standardized wax patterns with the same dimensions for the rest of the specimens. Ten identically-shaped threeunit frameworks were fabricated for each group. The dimensional accuracy of each of the specimens was controlled with a micrometer (Mitutoyo Absolute Digimatic; Mitutoyo Ltd, Hampshire, England).

The wax frameworks were sprued and invested with a speed investment material (IPS PressVEST Speed; Ivoclar Vivadent AG, Schaan, Liechtenstein). A lithium-disilicate glass-ceramic ingot (IPS e.max Press; Ivoclar Vivadent AG) was heated and pressed into an investment mold in the furnace (EP 600; Ivoclar Vivadent AG) after the burn out of the wax analogue. After divestment with glass polishing beads at 4 bar pressure, fine divestment was carried out with glass polishing beads at 2 bar pressure. The pressed frameworks were immersed into the $1 \%$ hydrofluoric acid (Invex Liquid; Ivoclar Vivadent AG) and clean in an ultrasonic cleaner (Whaledent Biosonic Jr. Whaledent International, Newyork, USA) for $15 \mathrm{~min}$. Subsequently, the object was cleaned under running water and blow dry. Sprues were cut with a diamond disk. The white reaction layer was removed carefully using aluminium oxide at 2
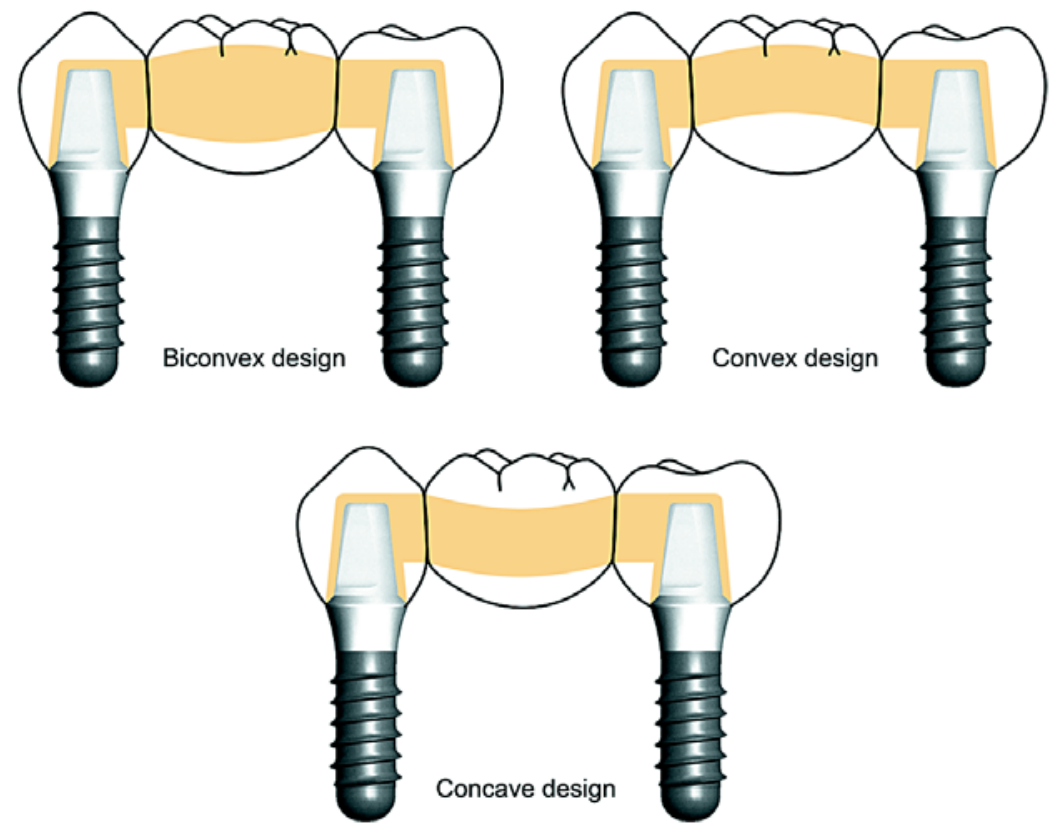

FIGURE 1- Pontic designs 


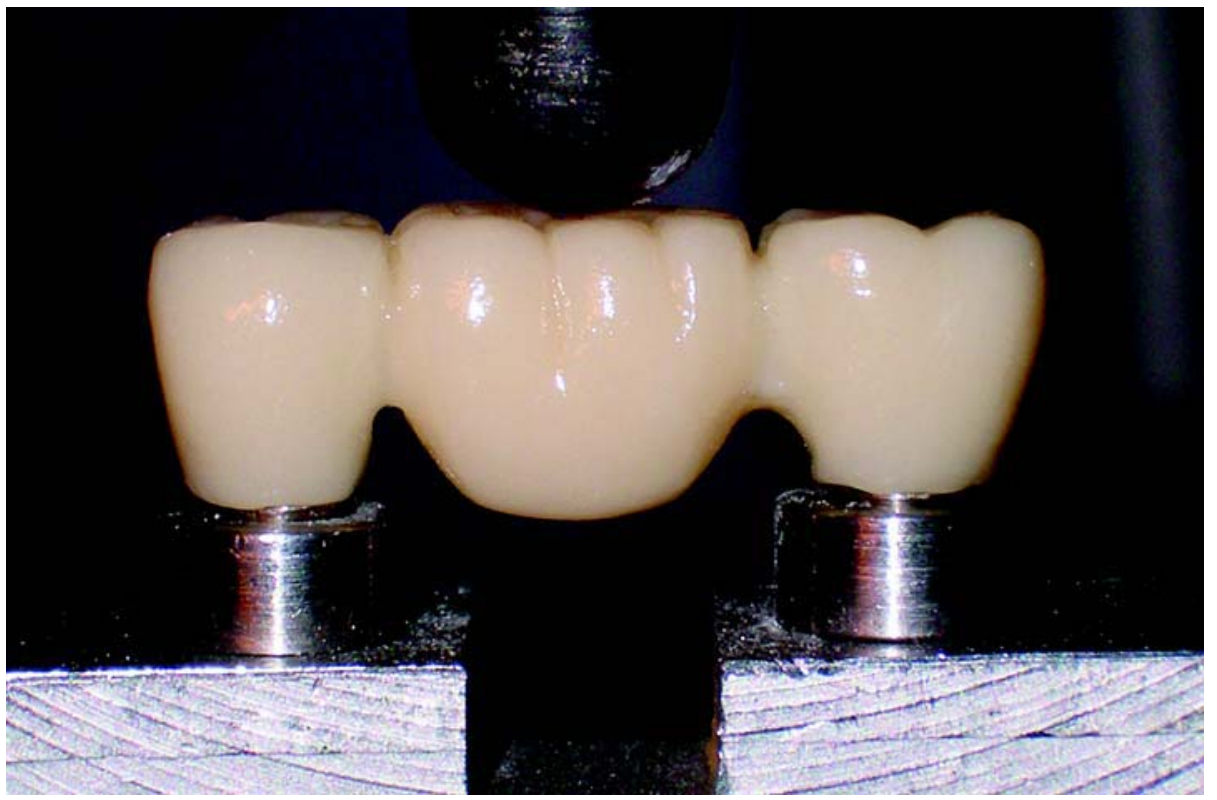

FIGURE 2- Three-unit all-ceramic fixed partial denture

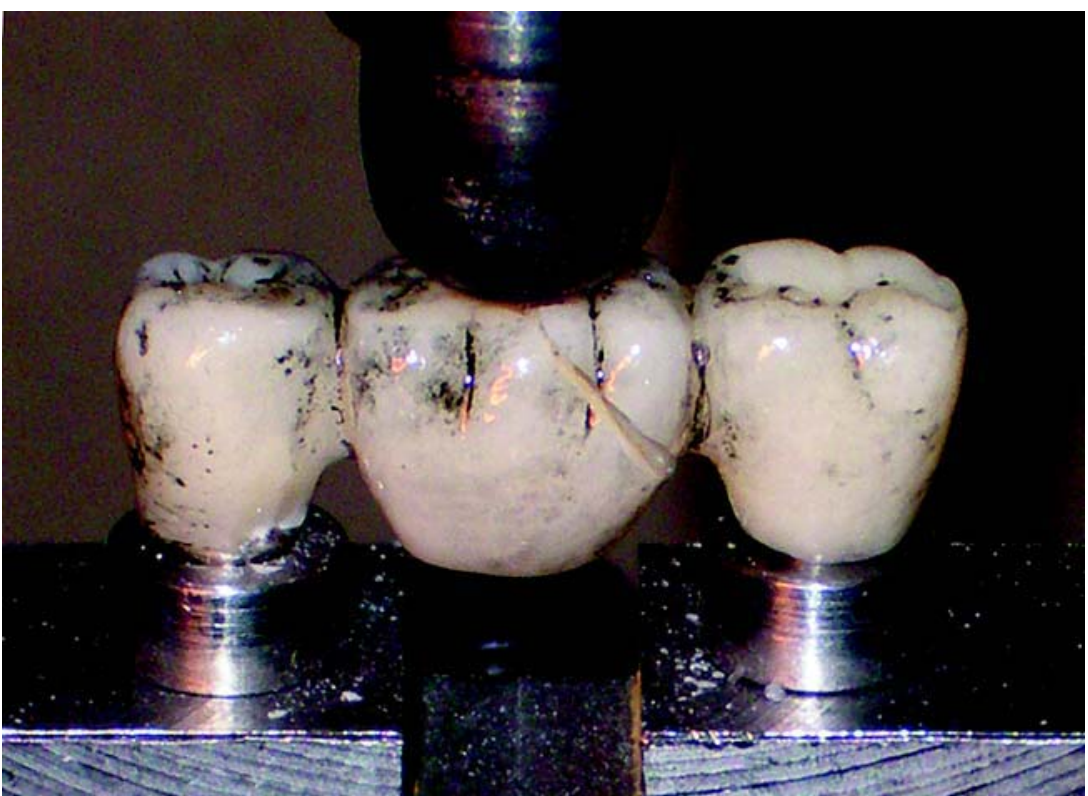

FIGURE 3- Example of a fractured fixed partial denture

bars.

To standardize the ceramic layer thickness, one framework for each group was veneered (IPS e.max Ceram Dentin A1, IPS e.max Ceram Transpa Incisal, IPS e.max Ceram Glaze Paste, Ivoclar Vivadent AG). Three silicone molds were manufactured for each group, allowing all other bridges to be veneered similarly. One type of porcelain was used for all specimens, and the manufacturer's instructions were followed. The protocol applied comprised dentin firing I and II, and glaze firing with glazing material. All frameworks were independently evaluated by 2 experienced clinicians using visual and tactile methods to ensure that the fit was acceptable. The shapes of the three-unit restorations are shown in Figure 1.
Each specimen was placed uncemented onto the abutments ${ }^{15}$. Axial compressive load was applied at central of pontic through steel ball (10.5 $\mathrm{mm}$ in diameter) (Figure $2)^{14,18,29}$. The fracture resistance of bridges was determined at a constant cross-head speed of $0.5 \mathrm{~mm} / \mathrm{min}$ on a universal testing machine (TSTM 02500, Elista Corp., Istanbul, Turkey). Loading was continued to the point of fracture, and values of failure loads $(\mathrm{N})$ were recorded with computer software. The crack initiation point on the load-versus-chartspeed curve for the all-ceramic bridges was determined by a sharp decrease in the loading curve and confirmed by an audible sound. Additionally, the location and nature of the fracture patterns was recorded and photographed by using a CCD camera (DFK 21AF04, The Imaging Source Europe 
$\mathrm{GmbH}$, Bremen, Germany) and a computer (Toshiba Satellite L10-102; Toshiba Europe GmbH, Hampshire, England) (Figures 2 and 3).

\section{Statistical Analysis}

The fracture resistance values of all specimens were analyzed statistically by Kruskal-Wallis and Mann-Whitney U tests. The groups were compared to verify the differences at a significance level set at $\mathrm{p}<0.05$ using the SPSS 11 for Windows statistical software (SPSS Inc., Chicago, IL, USA).

\section{RESULTS}

The fracture resistance values of bridges designed with biconvex, convex or concave pontics were 349.71, 438.20 and $300.78 \mathrm{~N}$, respectively. Kruskal-Wallis test revealed a significant difference $(p=0.026)$ between mean fracture loads according to type of pontic design (Table 1). Bridges designed with convex pontic showed the best mechanical properties as demonstrated by the high values of fracture resistance. However, no statistically significant differences $(p>0.05)$ were found between the fracture resistances of the groups, except for convex and concave groups $(\mathrm{p}<0.05$; $\mathrm{p}=0.009)$ (Table 1).

The fractures were located between the loading point and one of the connectors. The ways of crack propagation were mostly oblique gingivo-occlusally through the connector and pontic and parallel bucco-lingually to the occlusal surface along the occlusal embrasure (Figure 3). The fracture location occurred in the mesial or distal regions of the pontic (Table 2).

TABLE 1- Summary of the results obtained for fracture resistance

\section{Groups}

N Fracture load (N) [mean (SD)]

\begin{tabular}{lll}
\hline Biconvex design & 10 & $349.71(80.49)^{\mathrm{ab}}$ \\
Convex design & 10 & $438.20(117.27)^{\mathrm{a}}$ \\
Concave design & 10 & $300.78(100.23)^{\mathrm{b}}$ \\
\hline
\end{tabular}

Different letters indicate statistically significant difference at $5 \%$ level

\section{DISCUSSION}

All-ceramic bridges exhibited outstanding esthetics and excellent biocompatibility have been increasingly used during the past decade and today. Continuous development of both ceramic materials and fabrication techniques in addition to recent advances in bonding materials allowed for the introduction of new all-ceramic systems ${ }^{1,7,12,13}$. The mechanical properties of these systems have to meet the requirements needed to withstand the stresses and strains that can arise in this region because of the increasing use in posterior regions ${ }^{21}$.

Many studies on the fracture resistance of all-ceramic fixed partial dentures were investigated the effect of connector area and span of the pontic ${ }^{10,15,18,19,28}$. However, the shape of pontics may also influence the clinical performance of a restoration. Tsumita, et al. ${ }^{30}$ (2005) stated that the concave shape caused the highest maximum tensile stress, and high tensile stresses were appeared at the lower surface of pontic. Researchers also reported that convex design reduced the stress contrentration at the connector area of the gingival embrasure, and this pontic shape resisted the load as compressive stress. Kokubo, et al. ${ }^{14}$ (2007) evaluated the effect of straight, convex and concave pontic designs on the fracture resistance of implant-supported allceramic fixed partial dentures and declared that convex design is particularly useful for molar region. The results of present study agree with those of Tsumita, et al..$^{30}$ (2005) and Kokubo, et al. ${ }^{14}$ (2007). It is known that porcelain is weaker when stressed at tension and it is much stronger under compression $^{17}$. Tensile stresses tend to occur at lower surface of concave or straight beams by loading ${ }^{16}$. Also, the convex arches are the most efficient method of forming a structure with materials that have good compressive strength and low tensile strength ${ }^{16}$. Therefore, highest values of fracture resistance with respect to the other pontic designs studied were observed at convex design, while concave design showed lowest values of fracture resistance. Based on these results, the null hypothesis that different pontic designs would not affect the fracture resistance of all-ceramic restorations was rejected.

It has been reported that the mean adult occlusal force is about 400 to $800 \mathrm{~N}$ at the molar region, $300 \mathrm{~N}$ at the premolar region, and $200 \mathrm{~N}$ in the anterior region ${ }^{5}$. Oh and Anusavice ${ }^{18}$ (2002) stated that clinical contact areas on the pontic and the adjacent abutments may generate variations in the mode of failure in all-ceramic 3-unit bridges and ceramic prostheses may fail at values far lower than the mean values

TABLE 2 - The location and nature of fracture patterns

\begin{tabular}{llllr}
\hline Groups & \multicolumn{2}{c}{ Location of fracture } & \multicolumn{2}{c}{ Shape of fracture } \\
& $\mathbf{5 - 6}$ & $\mathbf{6 - 7}$ & Straight & Oblique \\
\hline Biconvex design & 4 & 6 & 1 & 9 \\
Convex design & 6 & 4 & 2 & 8 \\
Concave design & 3 & 7 & 2 & 8 \\
\hline
\end{tabular}


measured intraorally. All loads in this study were applied axially at the center of the pontic. The mean fracture loads for all designs were found lower than the mean maximum masticatory forces for molar region.

The present study has several limitations. Although luting can improve resistance of metal free restoration, FPDs were not cemented on the abutments in this study. This procedure may explain the low fracture resitance values. Also, lack of a thermomechanical loading is another limitation. Nevertheless, manufacturer suggested the use of IPS e.max Press system to remain limited with anterior and premolar regions, and there is no data about the use of this system at posterior region. Since the aim of the present study was to compare the effects of different designs rather than to assess the clinical performance, providing standard conditions for all test designs would be enough for evaluation. Thus, the inherent limitations in this study should be considered.

In the present study, cracks propagated obliquely through the gingival embrasure and pontic (directing from the gingival embrasure to the occlusal contact area) except for one specimen belonging to Group 3, at which the crack was between one of the connectors and pontic. The fracture surface was smooth and the failure origin was more difficult to detect. Oh and Anusavice ${ }^{18}$ (2002) and Sundh, et al. ${ }^{29}$ (2005) reported results similar to those of this study. The greatest incidence of fractures was observed in the premolarmolar connector for convex design. The findings indicate that the direction of force transmission for this design is different than the other two groups.

The major drawback of specimens with geometry similar to that of real prosthesis is the difficulty to prepare specimens with reproducible dimensions ${ }^{27}$. The core/veneer thickness ratio and the properties of the veneering porcelain have been shown to affect the resistance of bilayered core/porcelain specimens ${ }^{8,11,29}$. The connector's cross-section diameter, shape and position is founded to be important for the appropriate design of dental bridges ${ }^{10,18,19,28}$. In the present study, IPS e.max bridges were fabricated by the same dental technician by using silicone molds to standardize the ceramic layer thickness. In the same way as observed for several in vitro studies, it is difficult to extrapolate the results of this study directly to a clinical situation, and data obtained from current study must be supported by clinical investigations. Further studies that better simulate the oral environment and including thermomechanical loading are recommended.

\section{CONCLUSIONS}

Within the limitations of this study, the following conclusions can be drawn: 1 . The pontic designs were affected the fracture resistances of implant-supported allceramic fixed partial dentures; 2 . Convex design has higher potential than others to withstand occlusal forces.

\section{ACKNOWLEDGMENTS}

This study was supported by Selcuk University Scientific Research Coordination (BAP) and Ivoclar Vivadent AG.

\section{REFERENCES}

1- Attia A, Kern M. Influence of cyclic loading and luting agents on the fracture load of two all-ceramic crown systems. J Prosthet Dent. 2004;92:551-6.

2- Brägger U, Aeschlimann S, Bürgin W, Hämmerle CH, Lang NP. Biological and technical complications and failures with fixed partial dentures (FPD) on implants and teeth after four to five years of function. Clin Oral Implants Res. 2001;12:26-34.

3- Burke FJ, Watts DC. Effect of differing resin luting systems on fracture resistance of teeth restored with dentin-bonded crowns. Quintessence Int. 1998;29:21-7.

4- Chen HY, Hickel R, Setcos JC, Kunzelmann KH. Effects of surface finish and fatigue testing on the fracture strength of CAD-CAM and pressed-ceramic crowns. J Prosthet Dent. 1999;82:468-75.

5- Craig RG. Restorative dental materials. St Louis: CV Mosby; 1996.

6- De Jager N, Pallav P, Feilzer AJ. The influence of design parameters on the FEA-determined stress distribution in CAD-CAM produced allceramic dental crowns. Dent Mater. 2005;21:242-51.

7- Ferrari M, Cagidiaco MC, Vichi A, Mannocci F, Mason PN, Mjör IA. Bonding of all-porcelain crowns: structural characteristics of the substrate. Dent Mater. 2001;17:156-64.

8- Guazzato M, Proos K, Quach L, Swain MV. Strength, reliability and mode of fracture of bilayered porcelain/zirconia (Y-TZP) dental ceramics. Biomaterials. 2004;2:5045-52.

9- Johansson LA, Ekfeldt A. Implant-supported fixed partial prostheses: a retrospective study. Int J Prosthodont. 2003;16:172-6.

10- Kamposiora P, Papavasiliou G, Bayne SC, Felton DA. Stress concentration in all-ceramic posterior fixed partial dentures. Quintessence Int. 1996;27:701-6.

11- Kelly JR, Tesk JA, Sorensen JA. Failure of all-ceramic fixed partial dentures in vitro and in vivo: analysis and modeling. J Dent Res. 1995; $74: 1253-8$.

12- Kern M, Douglas WH, Fechtig T, Strub JR, DeLong R. Fracture strength of all-porcelain, resin-bonded bridges after testing in an artificial oral environment. J Dent. 1993;21:117-21.

13- Kheradmandan S, Koutayas SO, Bernhard M, Strub JR. Fracture strength of four different types of anterior 3-unit bridges after thermomechanical fatigue in the dual-axis chewing simulator. J Oral Rehabil. $2001 ; 28: 361-9$

14- Kokubo Y, Tsumita M, Sakurai S, Torizuka K, Vult von Steyern P, Fukushima S. The effect of core framework designs on the fracture loads of all-ceramic fixed partial dentures on posterior implants. J Oral Rehabil. 2007;34:503-7.

15- Lüthy H, Filser F, Loeffel O, Schumacher M, Gauckler LJ, Hammerle $\mathrm{CH}$. Strength and reliability of four-unit all-ceramic posterior bridges. Dent Mater. 2005;21:930-7.

16- Nageim H Al, Durka F, Morgan W, Williams D. Structural mechanics loads, analysis, design and, materials. Malaysia: Pearson Edu; 2003. 
17- O’ Brien WJ. Dental materials and their selection. Chicago: Quintessence; 1997.

18- Oh W, Anusavice KJ. Effect of connector design on the fracture resistance of all-ceramic fixed partial dentures. J Prosthet Dent. 2002;87:536-42.

19- Oh W, Gotzen N, Anusavice KJ. Influence of connector design on fracture probability of ceramic fixed-partial dentures. J Dent Res. 2002;81:623-7.

20- Raigrodski AJ, Chiche GJ. The safety and efficacy of anterior ceramic fixed partial dentures: a review of the literature. J Prosthet Dent. 2001;86:520-5.

21- Seghi RR, Denry IL, Rosenstiel SF. Relative fracture toughness and hardness of new dental ceramics. J Prosthet Dent. 1995;74:145-50.

22- Shillingburg HT, Hobo S, Whitsett LD. Pontics and edentulous ridges. In: Shillingburg HT, Hobo S, Whitsett LD, Jacobi R, Brackett SE, editors Fundamentals of fixed prosthodontics. Carol Stream, IL: Quintessence; 1997.

23- Sorensen JA, Cruz M, Mito WT, Raffeiner O, Meredith HR, Foser HP. A clinical investigation on three-unit fixed partial dentures fabricated with a lithium disilicate glass-ceramic. Pract Periodontics Aesthet Dent. 1999;11:95-106.

24- Stappert CF, Att W, Gerds T, Strub JR. Fracture resistance of different partial-coverage ceramic molar restorations: An in vitro investigation. J Am Dent Assoc. 2006;137:514-22.

25- Stappert CF, Guess PC, Gerds T, Strub JR. All-ceramic partial coverage premolar restorations. Cavity preparation design, reliability and fracture resistance after fatigue. Am J Dent. 2005;18:275-80.

26- Stappert CF, Stathopoulou N, Gerds T, Strub JR. Survival rate and fracture strength of maxillary incisors, restored with different kinds of full veneers. J Oral Rehbil. 2005;32:266-72.

27- Studart AR, Filser F, Kocher P, Lüthy H, Gauckler LJ. Mechanical and fracture behavior of veneer-framework composites for all-ceramic dental bridges. Dent Mater. 2007;23:115-23.

28- Studart AR, Filser F, Kocher P, Gauckler LJ. Fatigue of zirconia under cyclic loading in water and its implications for the design of dental bridges. Dent Mater. 2007;23:106-14.

29- Sundh A, Molin M, Sjögren G. Fracture resistance of yttrium oxide partially stabilized zirconia all-ceramic bridges after veneering and mechanical fatigue testing. Dent Mater. 2005;21:476-82.

30- Tsumita M, Kokubo Y, Ohtsuka T, Nakamura Y, Fukushima S, Steyern $\mathrm{P}$. Influences of core frame design on the mechanical strength of posterior all-ceramic fixed partial dentures. Part 1. Two dimensional finite element analysis. Tsurumi Univ Dent J. 2005;31:203-10 